\title{
How to Apply Sports Elements of National Tradition into Physical Education in A Reasonable Manner
}

\author{
Shaochang Yang, Jun $\mathrm{Hu}$ \\ College of Physical Education, Baoshan University, Baoshan, 678000, China
}

Keywords: Sports elements of national tradition, Physical education, Application

\begin{abstract}
This paper conducts an all-round analysis and discussion on the feasibility of applying elements of ethnic traditional sports into physical education, and elaborates the characteristics and advantages of ethnic traditional sports, reflecting the realistic significance of it. Furthermore, the paper discusses the problems in the practical application of ethnic traditional sports and presents the relevant suggestions so as to promote the development and progress of the physical education in our country.
\end{abstract}

\section{Introduction}

Ethnic traditional sports is the important way and approach to realize the education of ethnic traditional culture during the physical education in schools. The ethic traditional sport started long ago and covers an extensive range. Besides, it has lots of varieties and shows obvious cultural connotation of itself and peculiar characteristics and advantages. Therefore, Applying the elements of ethnic traditional sports into schools' physical education will make it rich both in variety and content. The approach will have a positive impact on the physical education as well as improving the quality level of physical education.

\section{Analysis of Specific Advantages of Applying the Elements of Ethnic Traditional Sports into Physical Education}

At current stage, with the deepening of education system reform, the reform for physical education curriculum is being carried out gradually. Under such context, the element of ethnic traditional sports is catching most people's attention. Meanwhile, the application of it in the physical education reveals its charm and advantages. The concrete detail is as following;

\section{Strong Resources in Reserve}

Schools possess a high-level and high-quality of teaching faculty and students. In the meantime, in addition to advanced teaching equipment and information exchanging system, teaching system is keeping updating and improving to become more modernized. Besides, teaching content and information resource is very rich. In addition, schools' physical education system is also improving. Therefore, it promote the application of ethnic traditional sports into physical education to some degree as well as provide strong support of human, material and intelligence resources.

\section{Advantages of Students Enrollment}

In most areas with a variety of nations, the minority students are actually the majority. Therefore, the percentage of minority students in schools is rather big. It is an obvious advantage when it comes to application of ethnic traditional sports into physical education and also provides an advantage for physical education.

\section{Powerful Ability of Promotion and Popularization}

Schools offer a large platform for the task of applying the elements of ethnic traditional sports into physical education. At the same time, the elements of ethnic traditional sports are grasping more and more attention. People are getting to know and understand, even research and take part in it, which shows a positive impact on the implementation of national fitness campaign and presents more 
exercise choices and methods. In addition, most schools promote the culture of ethnic traditional sports comprehensively through competition or culture and art exchange; thereby enhance the competiveness and influence of ethnic traditional sports elements of our country at home and abroad, which lays a solid foundation and favorable conditions for the internationalization of the culture of ethnic traditional sports.

\section{Enrichment of Culture Connotation of Physical Education in Schools}

The application and implementation of ethnic traditional sports elements in schools' physical education enrich the teaching form and content to some degree. Meanwhile, it breaks through the traditional physical education mode and changes the dull teaching in sports class. The application of ethnic traditional elements enriches the connotation of sports culture and also creates a more distinctive teaching content, method and form, which is beneficial to the improvement of the quality of physical education in schools.

\section{The Significance of Application of Ethnic Traditional Sports Elements in Physical Education}

In the course of spreading ethnic traditional sports elements, the main form of it is different from other cultures. The education function of ethnic traditional sports elements itself has determined its positive role in physical education. The form and content of ethnic traditional sports elements are rich and the different nations have different ethnic sports elements. Each nation's sports elements have their own unique culture connotation. The signification of applying ethnic traditional sports elements in physical education lies in following;

\section{Perfect Combination of Culture and Competition}

The competitive teaching is the most common teaching mode in schools' physical education. However, the competiveness in schools' physical education is rather different from marketization of competitive sports. The main purpose of physical education is to make students master the methods of fitness and at the same time contributes to the development of students, physically and mentally. Besides, it can enhance the cultural attribute of physical education course so as to better reflect the nature of education in the comparison between these two.

\section{Increase the Sports that Physical Beneficial and Interesting}

The physical beneficial and interesting of ethnic tradition sports lie in the popularity and it is easy to be spread. The most common sports are tug of war, rope skipping, swinging and so on. These kinds of sports can be widely used in the current physical education content. All these sports events have a realistic significance to improve students' team spirit and nature their spirit of collectivism. In the end, it can fulfill the goal of improving students’ physical fitness and strengthening sports exercises.

\section{Realization of Effect of Physical Education in An Entertainment Manner}

In fact, the ethnic traditional sports have its own nature of entertainment and fun. It also has the social function of improving affection, bringing pleasure mentally and physically and strengthening communication. In the schools' physical education, it can effectively cultivate the collectivism spirit for students and also animate the atmosphere in the class and improving mutual-assistance, mutual-learning, and mutual-communicating among students as well as to nature the collaboration spirit for students.

\section{Improvement of Aesthetic Appreciation of Techniques}

For ethnic traditional sports, fancy rope skipping, shuttlecock kicking and other sports events can give people an experience and feeling of visual beauty. In the meantime, rope skipping and shuttlecock kicking requires very little for the sport field and is not affected by the change of season. In the actual exercise of movement, the teaching can be tailored and combine the easy and the difficult. Students with different physical fitness can have the opportunity to take part in the sport that embodies the rich culture connotation of sports. 


\section{The Specific Operation Mode of Applying Ethnic Traditional Sports Elements in Physical Education}

\section{Club Teaching Model}

Club teaching model increase the entertainment and free space for the teaching to some extent. This model teaches in the form of club. According to the distribution of teaching content, the elements of ethnic tradition and other sports elements can be arranged together and the class can be divided into the basic class and advance class to conduct the teaching at different levels. At the same time, theory class can be set up that students can have a better knowledge and understanding of sports culture of ethnic tradition while taking part in the club teaching. In addition, when it comes to courses arrangement, students can be allowed to pick class in the range of fixed class time until they achieve the course credit.

\section{Salon Mode}

At current stage, Salon, as an important form of friend-making, getting-together and communication, is widely accepted by students. The solon mode can host regular and random party. And, most of the time, it is scheduled at night, which has no impact on students' class time. The attendees for salon are not so many. Most are voluntary and form a small circle of friends that speak freely and share their own views. As the connotation of ethnic traditional sports is very rich, it is perfect theme for a salon. The martial art can be taken as a topic that students can discuss the professional knowledge of martial arts and spiritual cultivation and so forth. Students can also experience the richness of ethnic traditional sports elements and know the culture and customs of different places and enhance their own culture and literacy.

\section{Society Model}

The society is the organization that enriches students' after-school life based on their different hobbies as well as improves their own comprehensive character. Sports society holds an important role in the societies of schools. It is open and allows all to take part in. The organizing of the society is flexible, in various forms, and it enrich the extracurricular life of students. Therefore, schools should support it with fund and field. Meanwhile, the elements of ethnic traditional sports should be incorporated in the society activities. Except for that, teaching departments of schools should assign professional teacher to guide and train the sports talents and enthusiasts. Furthermore, teachers should push the implementation and progress of ethnic traditional sports. Besides, schools can take the sport society outside of the school for better development and establish the schools' own characteristic.

\section{Model of Cultural Festival of Ethnic Sports}

Cultural festival activities can be launched in school that integrates the sports element of ethnic tradition into it so as to promote the application of ethnic traditional sports elements in physical education. This model not only can activate schools' cultural activities, but also cam make students know each other better in the course of participation and improve their national consciousness. Based on the different customs and festivals of different nations, the cultural festival of sports can be arranged accordingly. With the cultural festival of ethnic sports, it can create a united, harmonious and vigorous atmosphere in schools and fully reflect the spirit of national fitness.

\section{Model of Competition on Holidays}

Organizing competition activities in school during holidays can realize the application of ethnic traditional sports elements in physical education and enhance the physical exercises of teaching faculty and students. The theme of competition in holidays should be distinctive so as to create an active cultural environment of sports. It is also important for creation of sports culture in schools. The competition in holiday in schools can be divided into different levels, university level, college level, department level and grades level and etc. At the university level, they are mainly the competition held by the teaching department of the University for the Whole University. It can include the martial art, dragon competition into the competitions. As for the competition at the college level, they can be 
held by sports societies, holding bamboo stick jumping, reed-piping and so forth. At the department level and grade level, the forms of competitions are even richer. It can hold dual meet, invitation tournament and friendly competition and so on so as to promote the traditional ethnic sports culture.

\section{Advices and Suggestions for the Application of Ethnic Traditional Sports Elements in Physical Education}

\section{Approaching Closer to Modern Sports}

Compared ethnic traditional sports and modern sports, these two are interdependent. Ethnic traditional sports can learn from the merits of modern sports and develop it. Meanwhile, modern sports can also absorb the essence of ethnic traditional sports. Modern sports and ethnic traditional sports have their own advantages and characteristics, while ethnic traditional sports is more enjoyable for watching and more interesting and modern sports value more on competition. However, these two forms of sports can both promote exercise and fitness for people. Thus, it needs to apply ethnic traditional sports elements into physical education so as to inspire students and motivate them, which is beneficial for students, physically and mentally.

\section{Keep Improving in a Scientific Approach}

As the ethnic traditional sports have the characteristic of regional isolation, it will be good for the progress of ethnic traditional sports culture. Meanwhile, it can effectively enhance the national features and national cultural background. Due its inward limitation in the course of its development, it cannot match with the development of new things. However, the specific connotation of sports scientization is to develop and spread the ethnic traditional sports elements in a way that conform to the scientific law. At the same time, it is to sort and refine ethnic traditional sports elements with scientific principles. Making relevant adjustments and introducing more traditional sports with national features to be widely used in the physical education in accordance with the actual situation in schools.

\section{Conclusion}

As what has been mentioned above, ethnic traditional sports hold a prominent place in national culture, and ethnic traditional sports elements are the major components of it. Therefore, it is rich in forms and content as well as has the value of fitness, education and entertainment. At the current stage of physical education in schools in our culture, the modern sports education must be maintained, yet the education of ethnic traditional sports should also be carried out actively. It is necessary to know the ethnic traditional sports comprehensively and select distinctive elements to be applied in schools' physical education. In this way, it can not only ensure the all-round development for students, but also improve the quality of physical education, thereby make a great contribution to building harmonious society.

\section{Acknowledgments}

This paper is the annual philosophical and social project of Zhou Shan in 2015. The project is the practice research over sports resources of schools in Zhou San in the service of mass sports.

\section{References}

[1] Shibing Lu Study over the Operation Mode of Integrating Minority Traditional Sports Elements in Physical, Education of Colleges and Universities, 2014(11):7-9.

[2] Qingbing Sun, Yin Lin, Jiajin Zhou and etc. The Analysis on the Approach of Adaption Ethnic Traditional Sports in Campus on the Cases of Adaptation of Tea-picking Dance in Physical Education, Journal of Yu Lin Teachers College, 2014(5):78-82. 
[3] ]Xiaowei Peng, Guoqing Yang Re-analysis and Recognition of the Category of Current Physical Education. Journal of Sheng Yang Sports University, 2010,29(4):93-95.

[4] Zhiming Nie, Kangle Wang, Study over Characteristic of Traditional Physical Education Approach and Modern Physical Education Approach, Bulletin of Sport Science \& Technology, 2013,21(12):100-101.

[5] Yang Lau, Zhengjun Zhang Study over the Application of Ethnic Sports Elements in Physical Education- on the Case of Dao Lang Dance of Xin Jiang. Journal of Wu Han Institute of Physical Education, 2010,44(1):96-100. 